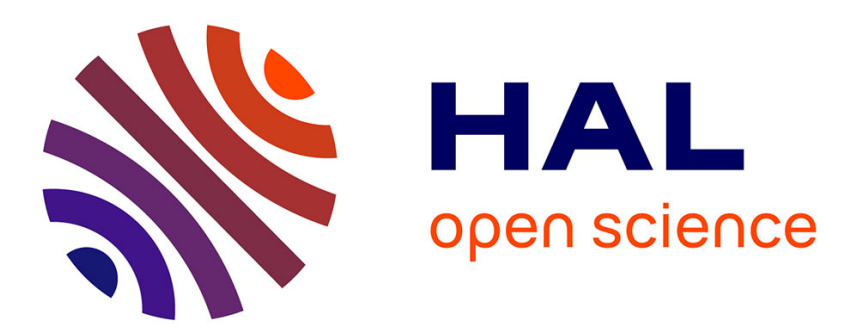

\title{
Flame shape transition in a swirl stabilised liquid fueled burner
}

Antoine Renaud, Sebastien Ducruix, Philippe Scouflaire, Laurent Zimmer

\section{To cite this version:}

Antoine Renaud, Sebastien Ducruix, Philippe Scouflaire, Laurent Zimmer. Flame shape transition in a swirl stabilised liquid fueled burner. Proceedings of the Combustion Institute, 2015, 35, pp.3365-3372. 10.1016/j.proci.2014.07.012 . hal-01189097

\section{HAL Id: hal-01189097 https://hal.science/hal-01189097}

Submitted on 28 Feb 2020

HAL is a multi-disciplinary open access archive for the deposit and dissemination of scientific research documents, whether they are published or not. The documents may come from teaching and research institutions in France or abroad, or from public or private research centers.
L'archive ouverte pluridisciplinaire $\mathbf{H A L}$, est destinée au dépôt et à la diffusion de documents scientifiques de niveau recherche, publiés ou non, émanant des établissements d'enseignement et de recherche français ou étrangers, des laboratoires publics ou privés. 


\title{
Flame shape transition in a swirl stabilised liquid fueled burner
}

\author{
Antoine RENAUD ${ }^{\mathrm{a}, \mathrm{b}, *}$, Sébastien DUCRUIX ${ }^{\mathrm{a}, \mathrm{b}}$, Philippe SCOUFLAIRE $^{\mathrm{a}, \mathrm{b}}$, Laurent ZIMMER ${ }^{\mathrm{a}, \mathrm{b}}$ \\ ${ }^{a}$ CNRS, UPR 288, Laboratoire d'Energétique Moléculaire et Macroscopique, Combustion (EM2C), Grande Voie des Vignes, 92290 \\ Châtenay-Malabry, France \\ ${ }^{b}$ Ecole Centrale Paris, Grande Voie des Vignes, 92290 Châtenay-Malabry, France
}

\begin{abstract}
A laboratory-scale two-stage swirling burner fueled with dodecane is studied experimentally with the help of high speed $(20 \mathrm{kHz})$ spray PIV and chemiluminescence imaging. For a lean operating point at $73 \mathrm{~kW}$, fuel staging is changed and a hysteresis cycle is highlighted. The flame is first lifted from the injector exit plane and exhibits a strong thermo-acoustic instability. The transition to a more stable state is studied by changing the staging parameter while keeping the power constant. Thanks to a well-controlled environment, several runs are performed to ensure that the phenomena observed during these transitions are reproducible. In less than $10 \mathrm{~ms}$, flashback happens in the inner recirculation zone and the flame attaches itself to the injector in a tulip-like shape. The spray then presents a wider angle. Thermo-acoustic instabilities are barely detected and the flame exhibits a strong response to the precessing vortex core. The flame finally widens into a more common V-shaped flame, either in less than $50 \mathrm{~ms}$ (for half of the experiments) or after more than $500 \mathrm{~ms}$.
\end{abstract}

Keywords:

Flame dynamics, bifurcation, staging control, flashback, precessing vortex core

\section{Introduction}

Because of environmental concerns, increasingly restrictive norms on pollutant emissions of gas turbine plants or aircraft engines have been set up in recent years. Traditionally based on diffusion regimes for reasons of safety and stability, combustion in gas turbines produces large amounts of pollutants such as nitrogen oxides (NOx) or carbon monoxide (CO). One of the numerous solutions envisaged is to switch to Lean Premixed Prevaporized (LPP) regimes where a more or less uniform lean mixture of fuel and air is supplied in order to reduce flame temperature and thus the emission of thermal NOx. However, when operated in lean conditions, gas turbines often exhibit strong combustion dynamics that may lead to stability issues such as combustion instabilities, flashback or blowout [1,2]. In particular, high amplitude self-excited oscillations can happen from the coupling between heat release and acoustic oscillations [3]. These interactions are known to be more

${ }^{*}$ Corresponding author: Laboratoire EM2C, Grande Voie des Vignes, 92290 Châtenay-Malabry, France

Email address: antoine.renaud@ecp.fr (Antoine RENAUD) easily triggered in premixed or partially premixed conditions [4]. To tackle this issue, injecting a small amount of fuel upstream leads to the creation of a piloting region that can help in stabilizing the system and reducing the coupling between pressure and heat release. Since multipoint injection leads to a fast and efficient mixing and fuel staging procedures enable the control of the spatial fuel distribution, multipoint staged injectors are good candidates for practical applications. However, their dynamics still have to be studied thoroughly and their impact on flame stabilisation remains yet to be fully understood. Indeed, the simulation of a single sector of an industrial gas turbine recently showed that two different flame stabilisations were possible for the same inlet conditions [5]. The transition between the two states was forced, either by changing the air and fuel flow rates or by strongly modulating them. The purpose of this paper is to present similar phenomena from an experimental point of view in a turbulent swirled multi-injection device fueled with liquid dodecane and to study the naturally occurring transition between two flame shapes. Despite being closer to practical applications, the use of liquid fuel leads to an increased complexity by adding key parameters such as droplet distribution or fuel evap- 
oration that strongly influence flame dynamics [6].

\section{Experimental setup and diagnostics}

\subsection{Experimental Setup}

The experimental device BIMER [7, 8] is equipped with a multipoint staged injector based on an industrial geometry where fuel and air can mix. The mixture then flows into a rectangular combustion chamber $\left(500 \times 150 \times 150 \mathrm{~mm}^{3}\right)$ with two side silica walls for optical access and three stainless steel water-cooled walls at the top, bottom and entrance of the chamber. Air, controlled by a mass flow controller (Bronkhorst In-Flow), is preheated (Sylvana SureHeat Max) to enhance fuel vaporization and then flows through a plenum before being divided between the two stages of the injector shown in Figure 1.

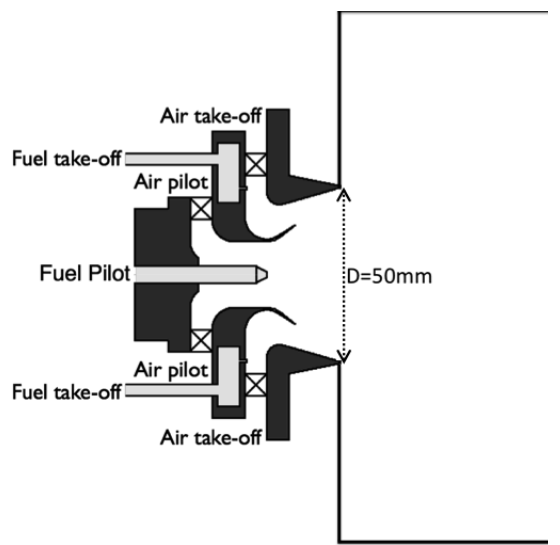

Figure 1: Lateral view of the injection device positioned at the entrance of the combustion chamber,showing the two fuel injection stages and their respective swirlers. Flow from left to right.

The upstream stage, called the pilot stage, contains an 18 -vane swirler that is designed to allow around $15 \%$ of the global air flow rate to flow through this stage. It is associated with a controlled fuel flow (Bronkhorst Mini Cori-Flow) in a central injection nozzle. This pressurized nozzle (MMP 6390-0-0-03) can inject up to $6.3 \mathrm{l} / \mathrm{h}$ of dodecane (flow number: $1.41 . \mathrm{h}^{-1} \cdot \mathrm{bar}^{-1 / 2}$ ), creating a hollow cone of droplets with a $30^{\circ}$ half angle.

The downstream stage, called the take-off stage, contains a 20-vane swirler through which the remaining $85 \%$ of the air flows. The fuel, controlled by a Coriolis flowmeter (Bronkhorst Cori-Flow), is injected through a multipoint device with ten equally spaced holes of 0.3 $\mathrm{mm}$ in diameter placed at the center of the exit of one swirler vane out of two to ensure proper droplet atomization.
The swirlers of each stage are co-rotating and designed to provide a geometrical swirl number close to 1.

The key parameter to this study being fuel staging, a fuel staging parameter named $\alpha$ has been defined to quantify the amount of fuel injected through the pilot stage [9]:

$$
\alpha=\frac{\dot{m}_{f, p}}{\dot{m}_{f, g}} \times 100 \%
$$

where $\dot{m}_{f, p}$ is the mass flow rate of fuel injected through the pilot stage and $\dot{m}_{f, g}$ is the total fuel flow rate. A value of zero then represents the fact that all the fuel is injected through the take-off stage while $\alpha=100 \%$ is associated with a pilot-only fuel injection.

In order to ensure a good repeatability between the experiments, the flowmeters are controlled through a in-house LabView software with a National Instruments PCI-6259 card.

For this study, a global equivalence ratio of 0.6 has been chosen with an air flow rate of $43 \mathrm{~g} / \mathrm{s}$. This leads to a thermal power around $73 \mathrm{~kW}$. Air is preheated at about $433 \mathrm{~K}$ and the combustion chamber is operated at atmospheric pressure. This operating point was chosen because it shows a strong response to variations of the staging parameter and enough stability to avoid blowoff. A previous study, carried out at a slightly higher operating point $(53 \mathrm{~g} / \mathrm{s}$ of air and same equivalence ratio), found a Sauter mean diameter $\mathrm{d}_{32}$ for the droplets around $15 \mu \mathrm{m}$. It lead to the conclusion that $\mathrm{d}_{32}$ was weakly dependent on $\alpha$ [7].

\subsection{Diagnostics}

The test bench is equipped with several sensors for acoustic and optical analysis. Four B\&K (4938) microphones placed in home-built water-cooled semi-infinite waveguides measure the pressure fluctuations in the plenum and along the chamber axis.

A high-speed camera (Photron Fastcam SA-5) is used to take images of the flame at a rate of $5 \mathrm{kHz}$. It is equipped with a $50 \mathrm{~mm}$, f:1.4 lens (Nikon). The region of interest is then of $150 \times 150 \mathrm{~mm}^{2}$ which allows the imaging of the full height of the chamber at the exit of the injector using the camera full frame $(1024 \times 1024$ pixels). No specific filter is used in order to avoid detrimental decrease of the light signal.

For some of the tests, simultaneous recording of the spray and flame positions at high rates is needed to gather further information on the system. The $\mathrm{CH}^{*}$ spontaneous emission from the flame is thus recorded at $20 \mathrm{kHz}$ with a first high-speed camera (Photron Fastcam SA-X) coupled with a light intensifier (Hamamatsu 
C10880-03C) and a 431( \pm 10$) \mathrm{nm}$ filter. With a $105 \mathrm{~mm}$ lens, the chamber is imaged on a $150 \times 150 \mathrm{~mm}^{2}$ region with $640 \times 640$ pixels. On the other side of the chamber, a second high-speed camera (Photron Fastcam SA-5) is equipped with a $50 \mathrm{~mm}$ lens and a $532( \pm 10) \mathrm{nm}$ filter to record the Mie scattering signal from the droplets. It is focused on a laser sheet placed vertically on the axis of the chamber and records a $110 \times 80 \mathrm{~mm}^{2}$ region with $704 \times 520$ pixels. The laser sheet is created with two Quantronix Nd:YAG lasers firing at $10 \mathrm{kHz}$ each with a delay of $20 \mu$ s between two pulses to enable the use of Particle Image Velocimetry (PIV) techniques.

The signals from the microphones and from the air and fuel flow-meters are acquired with a multiport acquisition card (National Instruments PCI-MIO-16E-4) at a frequency of $8192 \mathrm{~Hz}$.

\section{Operating point characterization}

As stated above, the operating point is chosen to be around $73 \mathrm{~kW}$ with an equivalence ratio of 0.6 . The global air flow rate is $43 \mathrm{~g} / \mathrm{s}$ and the corresponding fuel flow rate is $1.66 \mathrm{~g} / \mathrm{s}$. These flow rates are kept constant while the fuel repartition between the pilot and take-off stages is changed so that the staging parameter $\alpha$ varies between 0 and $50 \%$.

On Figure 2, the sound pressure level (SPL) in the chamber is plotted as a function of the staging parameter $\alpha$. Due to limitations on the acquisition duration at a proper sampling rate, four two-minutes runs were performed during which $\alpha$ is successively varied from $50 \%$ to $20 \%, 20 \%$ to $0 \%, 0 \%$ to $20 \%$ and finally $20 \%$ to $50 \%$. Between these runs, the flame is kept on to avoid any transient effect. Each second, the mean value of $\alpha$ and the SPL are computed and the associated point is plotted on the graph.

As $\alpha$ is decreasing, starting from $50 \%$, the SPL in the chamber is slightly increasing from 132 to $137 \mathrm{~dB}$ until $\alpha$ reaches very low values around a few percent. For very low $\alpha$, the SPL suddenly rises to $145 \mathrm{~dB}$ and the combustor reaches a high amplitude limit cycle due to a thermo-acoustic instability associated with the longitudinal quarter-wave mode of the chamber. This loud state remains until $\alpha$ increases back to about $20 \%$ where the sound pressure level drops to values similar to those obtained when decreasing $\alpha$.

A clear hysteresis cycle is then drawn and two different flame behaviours are shown to coexist for the same fuel staging depending on the path leading to this operating point. The main purpose of this paper is to study the flame state transition happening at the exit of the hysteresis cycle, from the loud state to the quieter one ( $\alpha$ close to $20 \%$ in Figure 2).

To gather enough data, 37 similar experiments were performed with slightly varying preheating temperatures (from 153 to $167^{\circ} \mathrm{C}$ ), depending on the preheating power and the ambient air temperature. In all these runs, the SPL in the chamber due to the thermo-acoustic instability ranges from 141 to $148 \mathrm{~dB}$ and the value of $\alpha$ at the instant of the transition (namely when the signal from the microphone drops) is on average $19.1 \%$ with minimum and maximum values of 16.8 and $21.8 \%$ respectively. This transition value is named $\alpha_{t}$ in the remaining of the paper. There seems to be a small impact of the preheating temperature on the value of $\alpha_{t}$ since the transition happens, on average, for smaller staging values when the preheating is higher. Despite this slight variability, the transition event itself remains the same and the flame and spray shapes before and after the transition do not change between runs.

\section{States before and after the transition}

During the transition event, not only does the SPL drop but the flame shape also changes dramatically. Durox et al. showed that different flame stabilizations for the same operating points led to different dynamic flame behaviours [10]. Before analysing this change in stabilization, it is first necessary to describe the states just before and just after the transition.

\subsection{Flame and spray shapes}

As stated in section 2, some of the experiments were performed with a simultaneous recording of the flame $\mathrm{CH}^{*}$ chemiluminescence and Mie scattering signal from the droplets. The Mie scattering images are treated with a PIV software (Dantec Dynamic Studio, adaptive correlation with 2 refinement steps, $16 \times 16$ final window size with $50 \%$ overlap) to obtain velocity fields which are then conditioned depending on the presence of droplets. From these treatments and recordings, mean droplet velocity and Abel-inverted mean $\mathrm{CH}^{*}$ spontaneous emission are computed before and $500 \mathrm{~ms}$ after the transition. During these $500 \mathrm{~ms}$ the injection conditions are almost constant as compared to the instant of transition, since this delay is below the liquid flowmeters characteristic timescale. The mean droplet velocity magnitude and flame shape are visible on Figure 3. On these mean images, it must be kept in mind that spray and flame can coexist in the same region because of intermittency. 


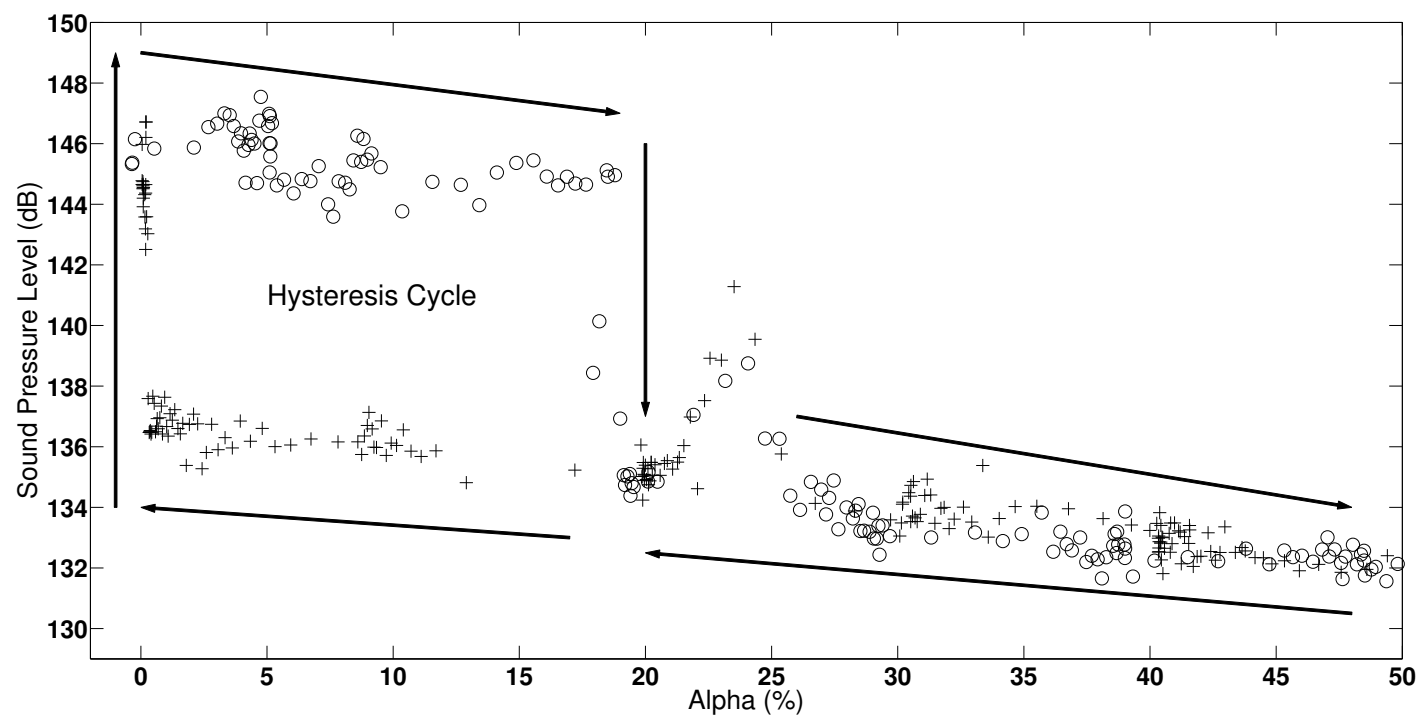

Figure 2: Evolution of the sound pressure level in the chamber as a function of the fuel staging parameter $\alpha$. The plus signs represent decreasing values and the circles increasing values of the staging parameter.
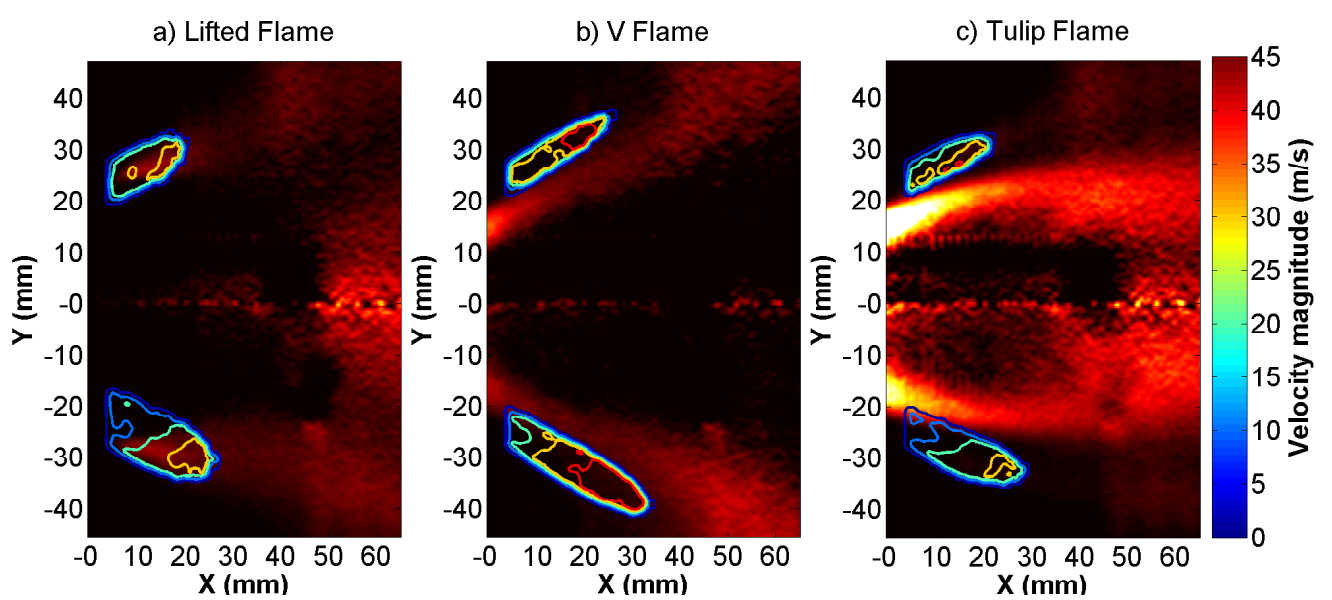

Figure 3: Abel-inverted mean $\mathrm{CH}^{*}$ chemiluminescence (image) and mean droplet velocity magnitude (contours) for the stable states before and after the transition. Flow from left to right.

Before the transition, as shown in section 3, the flame triggers a strong thermo-acoustic instability with, extracted from the 37 experiments, an average frequency of $329 \mathrm{~Hz}$ and minimum and maximum values of 320 and $344 \mathrm{~Hz}$. From the flame and spray shapes presented on Figure 3a, it can be noted that the mean spray is quite thick with a small half angle $\left(13^{\circ}\right)$. This comes from the fact that, because of the thermo-acoustic instability, the fuel droplets are spread over a much wider area in the chamber than for the quieter states. The fuel droplets in the spray have a mean velocity magnitude around $25 \mathrm{~m} / \mathrm{s}$. Most of the signal from the mean flame comes from the downstream part of the chamber and there is no signal around the injector lips. This means that the flame is not attached to the injector but lifted downstream in the chamber. Some signal however appears in the top and bottom parts of the upstream region $(\mathrm{Y}= \pm 30 \mathrm{~mm}$ ) because of intermittent reactions seemingly happening in the Outer Recirculation Zone (ORZ). Overall, the spray is mainly surrounded by the flame.

After the transition, two different states can be obtained and the resulting flame and spray shapes can be seen on Figures $3 b$ and $3 c$. Neither of these flames exhibit any thermo-acoustic instabilities even if large SPL values are still encountered due to broadband noise. On Figure $3 b$, the $V$ state, named after the shape of the 
flame, is visible. It occurred for 20 out of 37 experiments. The spray region is thinner than for the lifted state and has a wider half angle $\left(26^{\circ}\right)$. The mean velocity magnitude of the droplets is higher here than for the lifted case (more than $35 \mathrm{~m} / \mathrm{s}$ ), probably because of a smaller flow area due to the presence of the flame. On the contrary to the lifted state, the flame is surrounded by the spray and seems to have roots inside the injector, it can thus be considered as an attached flame. It has a wide angle and opens up downstream in a typical fashion for swirled flames $[11,12]$.

The flame and spray shapes for the second type of state that occurred after the transition for the remaining 17 runs out of 37 can be seen on Figure 3c. The spray in this state is quite similar to the one for the $V$-shaped flame albeit less opened $\left(17^{\circ}\right)$. The droplet velocity is however lower than in the $V$ case (around $30 \mathrm{~m} / \mathrm{s}$ ). The flame is also attached in the injector but it does not widen downstream and keeps a tulip-like shape. While the spray is mainly outside of the flame, some chemiluminescence signal can however be found further outside. These reaction zones $(\mathrm{Y}= \pm 30 \mathrm{~mm})$ are quite similar to those found for the lifted state because of the intermittency in the ORZ. The spray can then be considered as surrounded on both sides by the flame.

Although it seems steady over hundreds of milliseconds, this tulip state is however not completely stable and the flame eventually widens into a $V$-shaped flame after a few seconds. Despite the use of several methods, no discrimination criterion between the two states after the transition could be extracted from the global parameters (air and fuel flow rates, temperature, acoustic characteristics of the lifted state, etc).

\subsection{Dynamics of the attached states}

Dynamic Mode Decomposition (DMD) analyses [13] have been performed on the spontaneous emission data (600 samples at $5 \mathrm{kHz}$ ) for the $V$ and tulip states. Both of them exhibit a strong anti-symmetric mode around $2100 \mathrm{~Hz}$ (2081 Hz on average). Previous studies on the same setup [8] showed that this mode can be associated with a rotating helical vortical structure often found in flows with high swirl numbers, the Precessing Vortex Core (PVC) [14-17]. No PVC is detected in the lifted state, probably because of the thermo-acoustic instability as previously observed by Moeck et al. [18].

To allow comparisons between the runs, the impact intensity of the PVC on the flame is computed from the DMD spectrum as the height of the peak at the PVC frequency divided by the baseline (median value between 2000 and $2200 \mathrm{~Hz}$ ). The variability (computed with the same procedure on different parts of the same run) of this treatment is around \pm 0.2 , which is quite high but the amount of runs enable tendencies to be drawn. The resulting values are plotted as a function of $\alpha_{t}$ on Figure 4. For the $V$ flame, the impact of the PVC on the flame seems to be increasing with $\alpha_{t}$. This may be due to the fact that the main chemiluminescence intensity zone for higher values of $\alpha$ in the $V$ state seems to move a bit closer to the injector, which is where the PVC is more intense. A similar tendency can be observed for the tulip state even though the points are more scattered. Nevertheless, for a given $\alpha_{t}$, the tulip flame systematically shows a stronger response to the PVC than the $V$ flame.

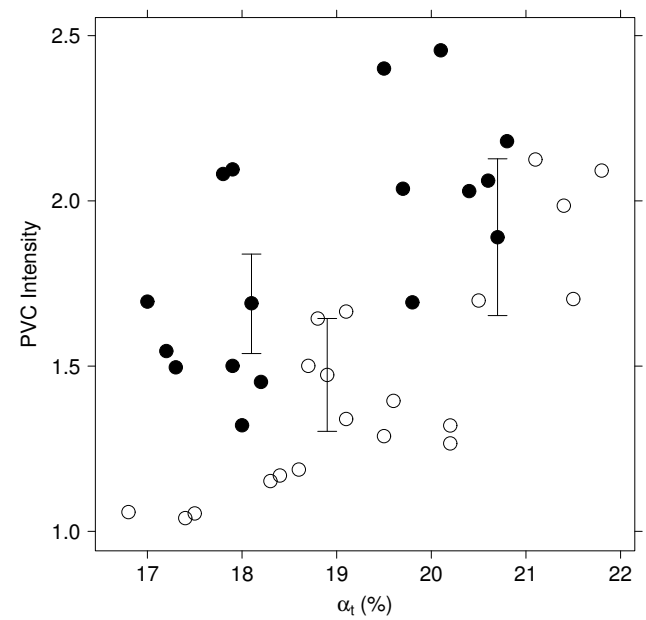

Figure 4: Intensity of the impact of the PVC on the flame after the transition versus the transition staging parameter $\alpha_{t}$ for the two attached states. Circles: $V$-shaped flame. Black dots: tulip-shaped flame. Three error bars are added to give an overview of the variability.

A similar DMD treatment has been performed on the Mie scattering images and the presence of an antisymmetric mode around $2100 \mathrm{~Hz}$ is detected for all the tulip and $V$ states. The PVC has then indeed an effect on the fuel spray. However, its intensity changes neither with $\alpha_{t}$ nor between the two states. What can be seen on Figure 4 is thus the result of the interaction between the PVC and the fuel vapor and/or the flame but does not reflect a change in the aerodynamical structure itself.

\section{Progress of the transition event}

Now that the states before and after the transition are clearly defined, the transition itself can be investigated. First, the evolution of the flame shape during the transition is studied and then focus is put on the very first step of the transition. 


\subsection{Evolution of the flame shape during the transition}

To follow the evolution of the flame shape during the transition and precisely define in which state the flame is, 2D-correlation is used. For each chemiluminescence frame recorded, three correlation coefficients associated with the mean flame shape of each stable state (lifted, tulip and $V$ ) are computed using the following formula:

$$
C_{M}(t)=\frac{\sum_{m} \sum_{n}\left(X_{m n}(t)-\bar{X}(t)\right)\left(M_{m n}-\bar{M}\right)}{\sqrt{\left(\sum_{m} \sum_{n}\left(X_{m n}(t)-\bar{X}(t)\right)^{2}\right)\left(\sum_{m} \sum_{n}\left(M_{m n}-\bar{M}\right)^{2}\right)}}
$$

where $X$ is the instantaneous image of the flame, $M$ the mean image of chemiluminescence in the considered state and the overline denotes the spatial averaging operation. A high correlation coefficient means that the instantaneous flame shape is sufficiently close to the mean flame shape of one of the stable states to be considered in this state. The evolution of these three correlation coefficients with the frame number (frame rate: $5 \mathrm{kHz}$ ) is plotted on Figure 5 for a typical transition that ends up with a $V$ flame.

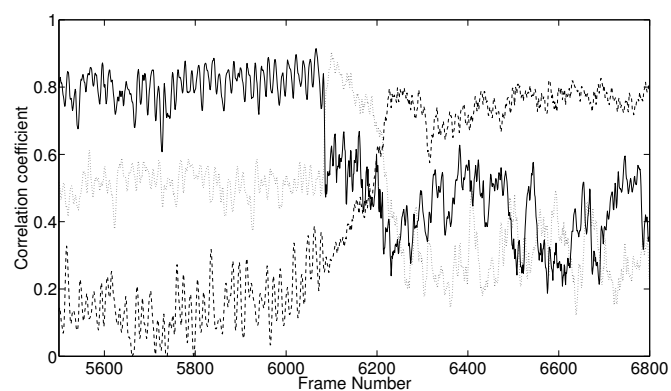

Figure 5: Evolution of the flame shape correlation coefficient during the transition. The solid line represents the correlation coefficient with the lifted flame, the dotted line the correlation with the tulip flame and the dashed line the correlation with the $V$ flame. The frame rate is $5,000 \mathrm{fps}$.

First, it can be seen that the transition itself is a very fast phenomenon since most of the graph shows either a very high correlation with the lifted state in the beginning or a high correlation with the $V$-shaped flame in the end. The change between the two states (ie the transition itself) actually happens between the frames 6000 and 6300, that is in the order of $50 \mathrm{~ms}$. An interesting feature in this window is that, for a few frames, the instantaneous flame shape correlates well with the mean shape of the tulip state and then ends up widening in the $V$ shape. It means that, even if it ends up in a $V$ shape, the flame always goes through a tulip phase. This behaviour is confirmed by the analysis of the whole set of transitions. Two steps can then be defined. The first one is the attachment of the flame from the lifted state to a tulip shape and the second one is the widening of the flame into a $V$ shape. This widening can occur a long time after the first step (more than half a second) meaning that the shape seen after $500 \mathrm{~ms}$ is still a tulip (figure $3 \mathrm{c})$. This second step may also occur very quickly and the final state is then a $V$ flame (figure $3 b$ ). In the latter case, the tulip shape lifetime ranges from 14 to $46 \mathrm{~ms}$ with an average value of $23 \mathrm{~ms}$ which is more than an order of magnitude shorter than the shortest stable tulip state described in section 4 .

\subsection{Focus on the attachment step}

The first step of the transition is the instant when the lifted flame gets anchored inside the injector with a tulip shape. It is studied using the intensified high-speed camera at $20 \mathrm{kHz}$ that allows a good decomposition of the flame motion. Several pictures extracted from the resulting movie are visible on Figure 6.

The first image (top left) shows an instantaneous lifted flame. The reaction zone is mainly located in the downstream part of the chamber, $30 \mathrm{~mm}$ away from the injection plane. On the next three images, a filament of flame can be seen in the center of the chamber, moving towards the injector. This is a flashback happening in the Inner Recirculation Zone (IRZ). This step takes one to two milliseconds to occur and the flame filament ends up igniting the injector region as can be seen on the fifth frame. This kernel of flame is then convected downstream by the flow on the next two pictures. This ends up in a tulip-shaped instantaneous flame visible on the last picture. This "ignition" phenomenon through a flashback inside the IRZ is the mechanism causing the change in the relative positions of the flame and spray. The effect of flashback in flame bifurcations was already highlighted by Huang et al. [19] in a numerical simulation. The main difference here is that the flashback happens in the IRZ and not near a wall.

Overall, the duration of this attachment phenomenon, from the lifted state to the tulip flame, is around 5 to $10 \mathrm{~ms}$. Interestingly, other similar IRZ flashbacks occur before the transition but they do not end up with a successful ignition inside the injector as the final one does. The key parameters associated with a successful ignition remain however yet to be found. As noticed in section 3, $\alpha_{t}$ seems to be lower for higher preheating temperatures, possibly an effect of fuel vaporization. Another key parameter is probably the instantaneous aerodynamic field inside the IRZ and the injector to ensure a proper flashback and a strong ignition in the premixing zone. Further techniques such as local timeresolved equivalence ratio measurements, which are out of reach for the moment, or 3D instantaneous velocity 

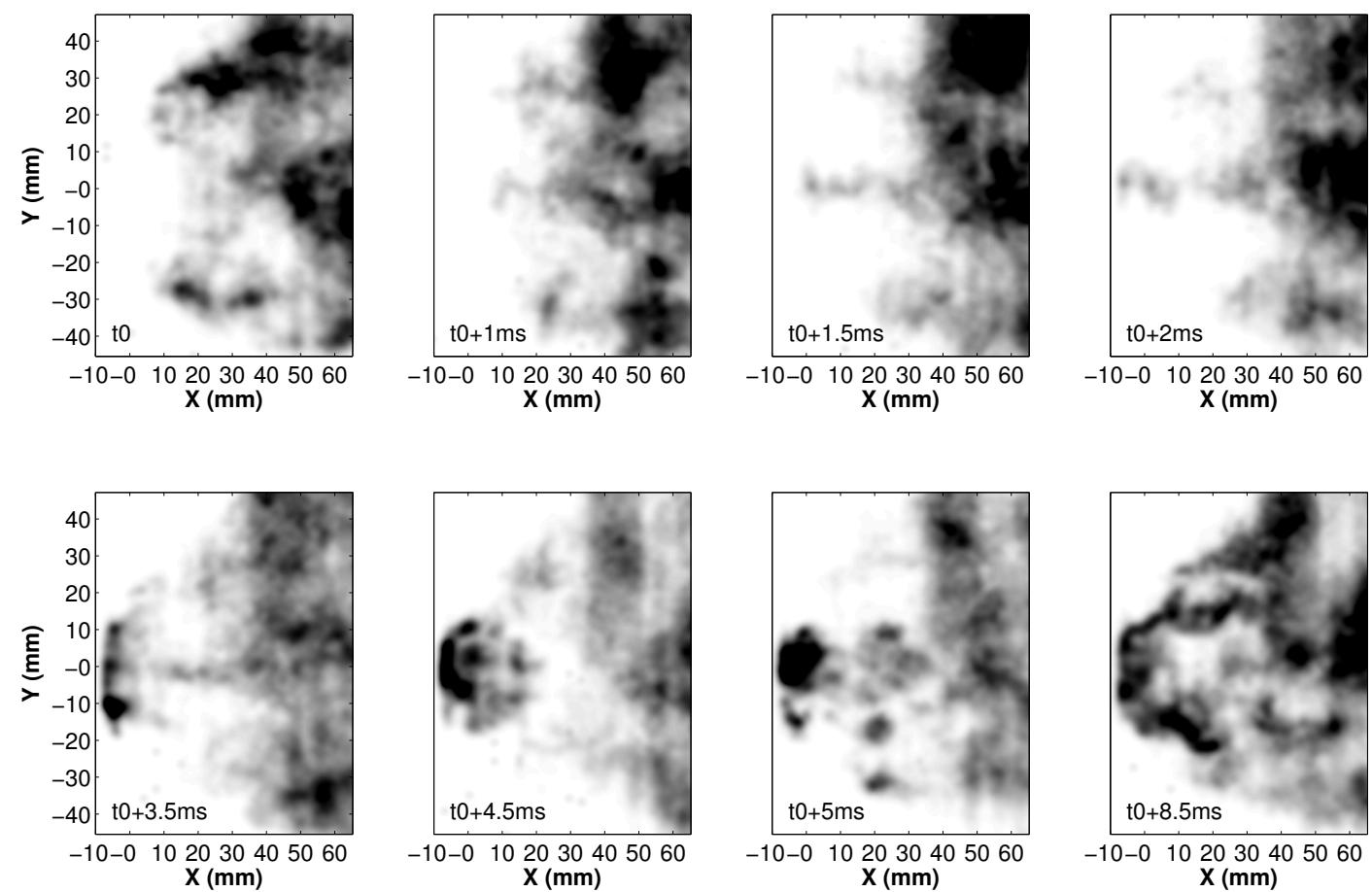

Figure 6: Evolution of the attachment step extracted from a $\mathrm{CH}^{*}$ chemiluminescence high speed movie $(20,000 \mathrm{fps})$. The camera is slightly tilted to allow a better imaging of the injector exit. A grayscale, saturated on the white (zero) side, is used to clearly identify the flame front propagation. Flow from left to right.

fields would clearly help in suggesting a proper mechanism for the phenomenon. A lead to follow up is the use of Global Rainbow Thermometry (GRT) [20] which may provide time-resolved average size and temperature of the fuel droplets in a probe volume.

\section{Conclusion}

Flame transitions in a well controlled turbulent swirlstabilised spray combustor were experimentally studied with time-resolved diagnostics. All the studied transitions switch form a lifted state with a strong thermoacoustic peak around $330 \mathrm{~Hz}$ to a tulip-like shape with a strong signature of an helical structure structure around $2100 \mathrm{~Hz}$ that is associated with the flow PVC. The transition scenario is an initial flashback in the center of the injector that forces the spray cone to open towards a wider angle and allows the flame to be entrapped in the IRZ. The obtained tulip flame eventually degenerates into a more conventional $V$-shaped flame, found in many pilot-stabilised burners.

While all transitions exhibit this scenario, they differ in the lifetime of the tulip shape, showing a bimodal distribution. About half of the events have a lifetime lower than $50 \mathrm{~ms}$ whereas the other half show lifetimes larger than $500 \mathrm{~ms}$. The fact that no widening happens between these two timescales leads to think that the process hidden behind is not entirely stochastic although its key parameters remain to be found.

To perform further investigation on this phenomenon, 3D diagnostics providing key values (aerodynamic field unsteadiness, local equivalence ratio) are needed as well as additional experiments to enable the use of powerful data analysis tools such as principal component analysis for example.

\section{Acknowledgements}

The authors would like to gratefully acknowledge Safran/Snecma for supporting this study. We also thank the technical staff at EM2C for their help in maintaining and upgrading the experimental setup.

\section{References}

[1] S. Candel, Proceedings of the Combustion Institute 29 (2002) 128.

[2] Y. Huang, V. Yang, Progress in Energy and Combustion Science 35 (2009) 293-364.

[3] W. Krebs, P. Flohr, B. Prade, S. Hoffmann, Combustion Science and Technology 174 (2002) 99-128. 
[4] S. Ducruix, T. Schuller, D. Durox, S. Candel, Journal of Propulsion and Power 19 (2003) 722-734.

[5] S. Hermeth, G. Staffelbach, L. Y. Gicquel, V. Anisimov, C. Cirigliano, T. Poinsot, Combustion and Flame (2013).

[6] M. de la Cruz Garcia, E. Mastorakos, A. Dowling, Combustion and Flame 156 (2009) 374-384.

[7] T. Providakis, L. Zimmer, P. Scouflaire, S. Ducruix, Journal of Engineering for Gas Turbines and Power 134 (2012).

[8] T. Providakis, L. Zimmer, P. Scouflaire, S. Ducruix, Comptes Rendus Mécanique 341 (2013) 4-14.

[9] S. Barbosa, P. Scouflaire, S. Ducruix, Proceedings of the Combustion Institute 32 (2009) 2965-2972.

[10] D. Durox, T. Schuller, N. Noiray, S. Candel, Proceedings of the Combustion Institute 32 (2009) 1391-1398.

[11] D. Galley, S. Ducruix, F. Lacas, D. Veynante, Combustion and Flame 158 (2011) 155-171.

[12] P. Weigand, W. Meier, X. Duan, W. Stricker, M. Aigner, Combustion and Flame 144 (2006) 205-224.

[13] P. J. Schmid, Journal of Fluid Mechanics 656 (2010) 5-28.

[14] N. Syred, Progress in Energy and Combustion Science 32 (2006) 93-161.

[15] H. Liang, T. Maxworthy, Journal of Fluid Mechanics 525 (2005) $115-159$.

[16] C. O. Paschereit, E. Gutmark, W. Weisenstein, AIAA journal 38 (2000) 1025-1034.

[17] M. Stöhr, I. Boxx, C. D. Carter, W. Meier, Combustion and Flame 159 (2012) 2636-2649.

[18] J. P. Moeck, J.-F. Bourgouin, D. Durox, T. Schuller, S. Candel, Combustion and Flame 159 (2012) 2650-2668.

[19] Y. Huang, V. Yang, Combustion and Flame 136 (2004) 383-389.

[20] J. P. A. J. van Beeck, D. Giannoulis, L. Zimmer, M. L. Riethmuller, Opt. Lett. 24 (1999) 1696-1698. 